\title{
Enantioselective Decarboxylation of 2-Methyl-2-aminomalonate Catalyzed by $(S)$-2-Hydroxy-2'-(3-phenyluryl-benzyl)-1,1'-binaphthyl-3-carboxaldehyde
}

\author{
Hyunjung Park, Raju Nandhakumar, Sunmin Lee, Yoonsu Ahn, and Kwan Mook Kim* \\ Department of Chemistry \& Division of Nano Sciences, Ewha Womans University, Seoul 120-750, Korea \\ *E-mail:kkmook@ewha.ac.kr \\ Received April 19, 2010, Accepted July 12, 2010
}

Key Words: Stereoselective decarboxylation, 2-Amino-2-methylmalonate, Imine catalysis, D-Amino acid

Aminomalonic acid $\left(\mathrm{AM}-\mathrm{H}_{2}\right)$ is a biological intermediate appearing in the conversion course of serine to glycine. ${ }^{1}$ Aminomalonic decarboxylases, enzymes that catalyze decarboxylation of aminomalonic acid, have been found in many living systems. ${ }^{2,3}$ Serine hydroxymethyltransferase stereospecifically decarboxylates 2-amino-2-methyl-malonic acid (MAM- $\left.\mathrm{H}_{2}\right)$ to produce D-alanine. ${ }^{4}$ Although stereoselective decarboxylation is a century old theme, ${ }^{5}$ the interest on it is growing recently owing to the development of chiral technology. ${ }^{6}$ Chemical approaches using metal complexes and cinchonine derivatives have been developed for stereospecific decarboxylation of MAM. ${ }^{7}$

Rate constant for the spontaneous decarboxylation of aminomalonate at $\mathrm{pH} 2-3$ and $25^{\circ} \mathrm{C}$ was reported to be $1.1 \times 10^{-6} \mathrm{~s}^{-1}$, which corresponds to half-life $\left(t_{1 / 2}\right)$ of $175 \mathrm{~h}^{7}$ In the presence of $1.0 \mathrm{M}$ acetone, the rate is enhanced to $\sim 100$-fold. ${ }^{8}$ Moreover, Thanassi reported a rate constant of $\sim 4 \times 10^{-3} \mathrm{~s}^{-1}$ for the 5-deoxypyridoxal catalyzed decarboxylation of MAM at $\mathrm{pH} 5$. $^{9}$ The rate enhancement in both cases are due to the imine formation. These studies encouraged us to employ $(S)$-2-hydroxy-2'-(3phenyluryl-benzyl)-1,1'-binaphthyl-3-carboxaldehyde (1) as a stereoselective chemical decarboxylase. Compound $\mathbf{1}$ was initially designed for stereoselective recognition of amino acids and amino alcohols by imine formation. ${ }^{10}$ We report here the decarboxylation of MAM catalyzed by $\mathbf{1}$.

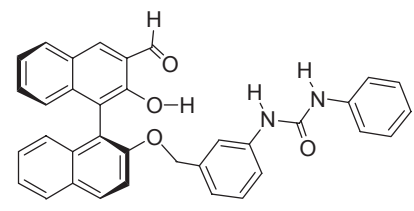

1

Compound 1 and neutral zwitterionic form of 2-amino-2methyl-malonic acid (MAM- $\left.\mathrm{H}_{2}\right)$ were synthesized according to the described methods. ${ }^{10,11}$

The spontaneous decarboxylation of MAM- $\mathrm{H}_{2}$ in DMSO- $d_{6}$ has been studied and compared with those of [ $\left.\mathrm{Me}_{4} \mathrm{~N}\right][\mathrm{MAM}-\mathrm{H}]$ and $\left[\mathrm{Me}_{4} \mathrm{~N}\right]_{2}[\mathrm{MAM}]$. The latter solutions were prepared by the addition of one and two equiv 1.0 M aqueous $\mathrm{Me}_{4} \mathrm{NOH}$, respectively, to the solution of MAM- $\mathrm{H}_{2}$ in DMSO- $d_{6}$. The final concentration of MAM was adjusted to be $20 \mathrm{mM}$, and the water content to be $10 \%$. The decarboxylation rates were determined by measuring the alanine methyl peaks in the ${ }^{1} \mathrm{H}$ NMR spectra of the solutions. The decarboxylation rate constant for the monoanionic form, [MAM-H] $]^{-}$, was determined to be $(2.3 \pm$
$0.2) \times 10^{-7} \mathrm{~s}^{-1}\left(t_{1 / 2}=837 \mathrm{~h}\right)$, whereas the one for MAM-H $\mathrm{H}_{2}$ to be $(7.3 \pm 0.2) \times 10^{-6} \mathrm{~s}^{-1}\left(t_{1 / 2}=26 \mathrm{~h}\right)$ and the one for $[\mathrm{MAM}]^{2-}$ to be $(3.0 \pm 0.6) \times 10^{-6} \mathrm{~s}^{-1}\left(t_{1 / 2}=64 \mathrm{~h}\right)$ (Supporting Information).

The decarboxylations of MAM- $\mathrm{H}_{2},[\mathrm{MAM}-\mathrm{H}]^{-}$and $[\mathrm{MAM}]^{2-}$ in the presence of compound $\mathbf{1}$ has been studied by ${ }^{1} \mathrm{H}$ NMR also in DMSO- $d_{6}$ solutions (Supporting Information). Figure 1 shows the time-dependent ${ }^{1} \mathrm{H}$ NMR spectra for the solution of $\left[\mathrm{Me}_{4} \mathrm{~N}\right][\mathrm{MAM}-\mathrm{H}]$ mixed with compound $\mathbf{1}$ in $1: 1$ equivalent. The spectra of the initial solutions were too complex to discern the species being produced. As time passed, however, the signals of the imine formed between $\mathbf{1}$ and decarboxylated product alanine began to grow from other unidentifiable signals, and the imine became only one dominating species in the solution in $\sim 10 \mathrm{~h}$. The spectra strongly supported the stereoselective decarboxylation because the imine formed between $\mathbf{1}$ and D-Ala

(d)

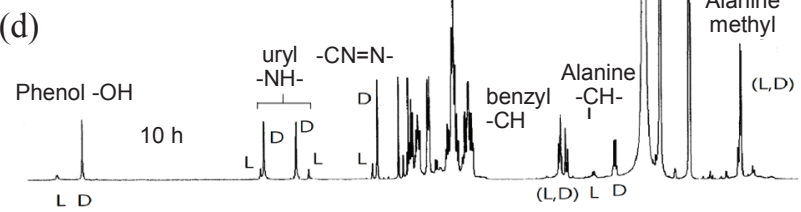

(c)

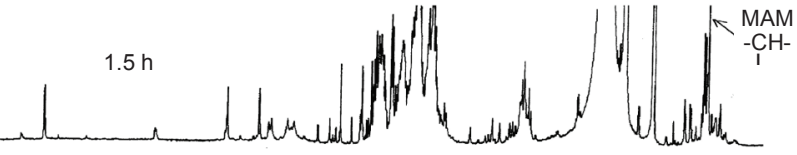

(b)

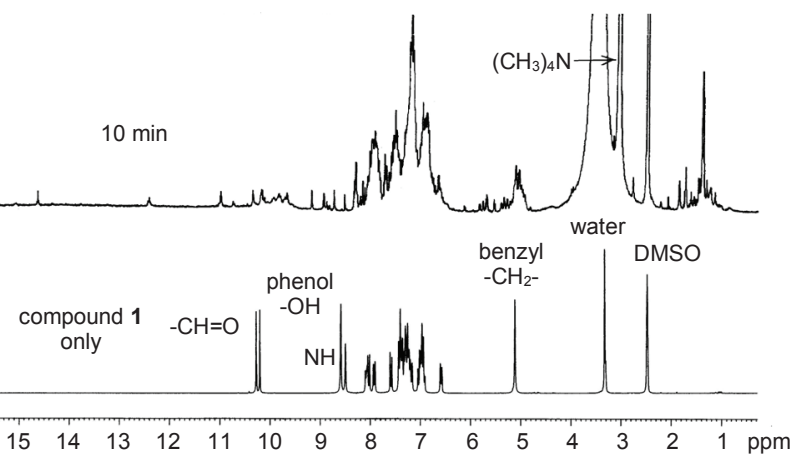

Figure 1. (a): The ${ }^{1} \mathrm{H}$ NMR spectrum of DMSO- $d_{6}$ solution of 1 only. (b)-(d): The ${ }^{1} \mathrm{H}$ NMR spectra of DMSO- $d_{6}$ solution of $\mathbf{1}+\left[\mathrm{Me}_{4} \mathrm{~N}\right]$ [MAM-H] in $10 \mathrm{~min}, 1.5 \mathrm{~h}$ and $10 \mathrm{~h}$. All the peak assignments in (d) are for the imines of 1-D-Ala and 1-L-Ala, and the peak assignment in (b) and (c) is for free $\left[\mathrm{Me}_{4} \mathrm{~N}\right][\mathrm{MAM}-\mathrm{H}]$. 
Table 1. The ee values of the D-alanine produced from the decarboxylation of $\left[\mathrm{Me}_{4} \mathrm{~N}\right][\mathrm{MAM}-\mathrm{H}]$ in the presence of varied stoichiometric amount of 1

\begin{tabular}{ccc}
\hline $\begin{array}{c}\text { Stoichiometry } \\
\left(\mathbf{1}:[\mathrm{MAM}-\mathrm{H}]^{-}\right)\end{array}$ & $\begin{array}{c}\text { time to completion of } \\
\text { decarboxylation }\end{array}$ & $e e$ \\
\hline $1: 1.0$ & $3 \mathrm{~h}$ & $67 \%$ \\
$1: 3.1$ & $20 \mathrm{~h}$ & $62 \%$ \\
$1: 5.2$ & $24 \mathrm{~h}$ & $54 \%$ \\
$1: 9.1$ & $48 \mathrm{~h}$ & $42 \%$ \\
$1: 17$ & $72 \mathrm{~h}$ & $38 \%$ \\
\hline
\end{tabular}

(1-D-Ala) was produced $\sim 5.1$ times more than 1-L-Ala. The peak assignments are described in the figures. The half-life of $[\mathrm{MAM}-\mathrm{H}]^{-}$in the presence of compound $\mathbf{1}$ is roughly $2 \mathrm{~h}$, which is much faster than that of the corresponding spontaneous case, $837 \mathrm{~h}$.

The similar ${ }^{1} \mathrm{H}$ NMR studies for the solutions of MAM- $\mathrm{H}_{2}$ and $\left[\mathrm{Me}_{4} \mathrm{~N}\right]_{2}[\mathrm{MAM}]$ in the presence of one equivalent of 1 revealed also that their decarboxylations were faster than those of the corresponding spontaneous cases. The stereoselectivities for D-Ala to L-Ala, however, were much less than the monoanion case, only 1.3:1 for MAM- $\mathrm{H}_{2}$ case and 1.2:1 for the dianion case.

It could be concluded from the studies above that the decarboxylation of monoanionic form of MAM in the presence of 1 occurs much faster than the spontaneous case and moreover more stereoselectively compared to the dianion or neutral form. Therefore, we chose monoanionic form of MAM in further decarboxylation studies to reveal catalytic effect of compound $\mathbf{1}$.

In order to assess the catalytic property of compound $\mathbf{1}$, we varied the stoichiometry of 1 to $[\mathrm{MAM}-\mathrm{H}]^{-}$and investigated the enantiomeric excess (ee) values of the decarboxylated product, alanine. The ee values were determined by ${ }^{1} \mathrm{H}$ NMR integration using compound $\mathbf{1}$ as a chiral shift reagent. The detailed experimental procedures were given by Supporting Information. The experimental results are listed in Table 1. A longer time was required to complete the decarboxylation of the [MAM-H] $]^{-}$as the ratio of $\mathrm{MAM}-\mathrm{H} / \mathbf{1}$ increases. This result reveals that the decarboxylation is a stereoselective catalytic process. The decrease of the $e e$ values upon the increase of MAM-H/1 ratio is probably due to the spontaneous decarboxylation and/or partly by some unknown non-stereoselective decarboxylation process.

Even though the mechanism for the catalytic stereoselective decarboxylation in the presence of $\mathbf{1}$ was not clearly revealed in these studies, the imine formation between $\mathbf{1}$ and MAM could be proposed as one route leading to the stereoselective consequence because the imine formation could activate the decarboxylation and trans-imination could also lead to the catalytic reaction. The energy minimized structure calculated by Molecular Mechanics computation ${ }^{13}$ for the possible imine intermediate, [1-MAM-H] $]^{-}$, is shown in Figure 2a. The structure shows that one carboxylate is protonated whereas the other is hydrogen bonded to uryl group, and the proton on one carboxylate is hydrogen bonded to the other carboxylate forming a cyclic transition state. Since the removal of the protonated carboxylate group produces D-alanine, the route drawn in Figure $2 \mathrm{~b}$ can be proposed as a possible decarboxylation mechanism.

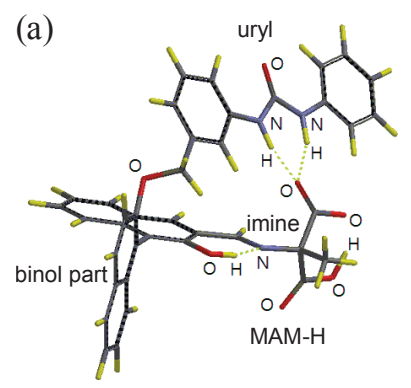

(b)

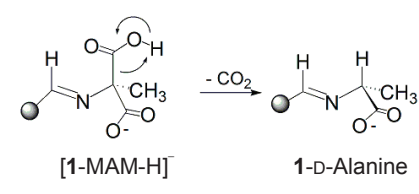

represents the part of 1

Figure 2. (a): The energy-minimized structure for [1-MAM-H] $]^{-}$(b): A proposed route to the decarboxylation.

In summary, we have demonstrated that the chiral aldehyde 1 catalyzes the stereoselective decarboxylation of [MAM-H] . The stereoselectivity is maximum in monoanionic form of MAM. The D-form-favor in the decarboxylation may be explained by the removal of the protonated carboxylate group and protonation at the same site.

Acknowledgments. This research was supported by the Ministry of Science and Technology of Korea through NRL (2010-0008022) and SRC program of MOST/KOSEF at Ewha Womans University (20090063002).

\section{References}

1. (a) Thanassi, J. W. Biochemistry 1970, 9, 525. (b) Knoop, F. Physiol. Chem. 1914, 89, 151.

2. Shimura, K.; Nagayama, H.; Kikuchi, A. Nature 1956, 177, 935.

3. Thanassi, J. W.; Fruton, J. S. Biochemistry 1963, 1, 975.

4. Thomas, N. R.; Rose, J. E.; Gani, D. J. Chem. Soc., Perkin Tran. 1 $1993,2933$.

5. (a) Marckwald, W. Ber. Dtsch. Chem. Ges. 1904, 37, 349. (b) Marckwald, W. Ber. Dtsch. Chem. Ges. 1904, 37, 1368.

6. (a) Kim, S. G.; Sambasivan, S.; Ahn, K. H. Bull. Korean Chem. Soc. 2010, 31, 724. (b) Hyun, M. H.; Kim, S. N.; Choi, H. J.; Sakthivel, P. Bull. Korean Chem. Soc. 2007, 28, 1419.

7. (a) Amere, M.; Lasne, M.-C.; Rouden, J. Org. Lett. 2007, 9, 2621. (b) Brunner, H.; Baur, M. A. Eur. J. Org. Chem. 2003, 2854. (c) Yashiro, M.; Miura, S.; Matsuyama, T.; Yoshikawa, S.; Komiyama, M.; Yano, S. Inorg. Chem. 1994, 33, 1003. (d) Toussaint, O.; Capdevielle, P.; Maumy, M. Tetrahedron Lett. 1987, 28, 539. (e) Goodwin, T. J.; Mulqi, M. W.; Williams, P. A. Inorg. Chim. Acta 1985, 98, 141. (f) Ajioka, M.; Yano, S.; Matsuda, K.; Yoshikawa, S. J. Am. Chem. Soc. 1981, 103, 2459. (g) Glusker, J. P.; Carrell, H. L.; Job, R.; Bruice, T. C. J. Am. Chem. Soc. 1974, 96, 5741.

8. Callahan, B. P.; Wolfenden, R. J. Am. Chem. Soc. 2004, 126, 4514.

9. Thanassi, J. W. Biochemistry 1972, 11, 2909.

10. (a) Park, H.; Kim, K. M.; Lee, A.; Ham, S.; Nam, W.; Chin, J. J. Am. Chem. Soc. 2007, 129, 1518. (b) Kim, K. M.; Park, H.; Kim, H. J.; Chin, J.; Nam, W. Org. Lett. 2005, 7, 3525.

11. (a) Sun, S.; Zabinski, R. F.; Toney, M. D. Biochemistry 1998, 37, 3865. (b) Bailey, G. B.; Chotamangsa, O.; Vuttivej, K. Biochemistry $1970,9,3243$.

12. (a) Filer, C. N.; Lacy, J. M.; Peng, C. T. Syn. Commun. 2005, 35, 967. (b) Liauger, L.; Cosa, G.; Scaiano, J. C. J. Am. Chem. Soc. 2002, 124, 15308. (c) Hunter, D. H.; Hamity, M.; Patel, V.; Perry, R. A. Can. J. Chem. 1978, 56, 104.

13. Molecular mechanics computation was performed using Spartan '02 Windows from Wavefunction, Inc. 